\title{
CULTURAL CONFLICT AND PUBLIC SPACE: A NEW CONCEPTUALIZATION
}

\author{
FRANCISCO GONZÁLEZ DE CANALES ${ }^{1} \&$ NURIA ÁLVAREZ LOMBARDERO ${ }^{2}$ \\ ${ }^{1}$ Department of History and Theory, University of Seville, Spain \\ ${ }^{2}$ Architectural Association School of Architecture, London, UK
}

\begin{abstract}
Since the definition of the global city in the 90s, our understanding of the generic city has been that of a formless, diluted, urban mass ineluctably moving towards complete homogenization and the subsequent dilution of character. However, cultural positions on how city spaces are lived in today seem to be more polarized than ever. The increasing mobility of population transnationally has emphasised this polarization, and is mainly seen in large, global metropolises. Today, cultural conflicts are not happening between regions and nations, but are unfolding at the scale of the city. In opposition to ideas that understood cultural conflict as either an increasing revelation of an abstraction that alienates subjectivity - as suggested by Marxist critics - or a tumultuous path before the triumph of the generic and homogenous city - as in the 90s - this paper will explore the concept of "transculturation" and navigate through this new socio-cultural and spatial situation in cities. According to the concept of transculturation, taken from the Latin-American critical theory tradition as an alternative tool to analyse cultural conflict in the city, the cultural reality of the city is always defined by specific and concrete truths through a relentless process of contrast and debate and by power relations that are continuously defined and redefined at various scales. Focusing on the notion of public spaces and its production as a critical means of exploring urban cultural conflict today, this paper will examine the theoretical bases for a culturally sustainable public space, taking as precedents both the square under the Museum of Art of Sao Paulo designed by Lina Bo Bardi and the more recent and collectively designed Gillet Square in Dalston, London.
\end{abstract}

Keywords: transculturation, sustainable public spaces, transcultural collective urbanism.

\section{INTRODUCTION}

In his canonical text about the generic city, architect Koolhaas [1], offers us blurred images of urban landscapes, amid an implicit apology for the emptying of cultural identity that the contemporary city was witnessing. Questioning the contextualism status quo of the early $90 \mathrm{~s}$, as evinced in the Anywhere Conference [2], and in relation with his personal experience and life with hotels and airports, Augé [3], offers another facet to Marc Augé's pessimistic view on contemporary "non-places", precisely exemplified by the hotel, the shopping mall and the airport. In this way, the Dutch architect presents the advance of the generic as the advance of the equitable, common, or what might be the real embodiment of the modern dream of egalitarianism. As Koolhaas states [4]: "what if this seemingly accidental-and usually regretted-homogenization were an intentional process, a conscious movement away from difference toward similarity? What if we are witnessing a global liberation movement: "down with character!"

However, if seen from today, the results of modernization seem increasingly more tangible than those described in Koolhaas' early reflections on the generic city. In Koolhaas' text, we can still recall Virilio's [5], warnings on the disappearance of the object that was so persistent in the Anglo-Saxon academia of the 1990s. But the reality is that in a generic downtown, a commercial pedestrian street, a shopping mall or an airport, we just need to move a bit to their backstage, or a couple of blocks away, to be exposed to very specific spatial experiences that never truly repeat. Therefore, the place later defined by Koolhaas [6], 
as "junk space", where the escalator intersects with the air-conditioning duct, where urbanity is established as a mantle of internal security and where conflict, intermittency and even the outside seem eradicated, is today full of particularities when looking at what is hidden in its interstices.

Globalisation can be seen as the dissolution of tangibility, but also as the movement that lead us irremediably towards a less critical reality; a reality void of coherence and consistency, and instead to one prodigiously leaking authenticity, and where reality and simulacra are indistinguishable -leading to a complex and alienating experience for the ordinary citizen. However, this reading preached by various cultural critics, such as the very popular reflection by Baudrillard [7], in the $90 \mathrm{~s}$, is useless today. The criticism based on the lack of authenticity appears absolutely reactionary, fed more by fear than by facts. In fact, was it ever possible to define essences of the authentic without it being an authoritarian imposition on the real? What other purpose could the definition of the essence of being have but that of imposing a canon of its reading?

Actually, the experience of globalisation is not only that of a city composed of suburban housing and shopping malls, but also, one of another kind. We are referring to a reality that can be observed any day in a London neighbourhood such as Whitechapel, where Caribbean, Central African, European, Indian, Bangladeshi and Middle Eastern people live together creating one of the liveliest and most diverse neighbourhoods in the city today. Examples like this reveal that globalisation happens not so much through generic objects and experiences, but through very real elements arriving from different cultures and ethnic groups, frugally finding each other in different parts of the globe. One of the consequences of this phenomenon is that culture is no longer fixed to a territory or region, but has become a patrimony of these individuals or communities' practice in the urban space. To understand these dynamics from a new perspective, one that is different from that prevailing since the 1990 s, we will introduce to this text the concept of transculturation.

\section{THE TRANSCULTURAL TRADITION}

The assimilation of the cultural experience in the contemporary metropolis and how it challenges our traditional understanding of identity it is still an on-going debate. Throughout the 90 s, the discussion of a new emerging cultural reality in the global metrópolis centred the debate around two alternatives: multiculturalism and multi-communitarianism. Multi-communitarianism would foster cultural isolation in homogeneous communities within heterogeneous urban territories, producing ghettos and tensions between different established communities. Multiculturalism, on the other hand, would promote a new type of cultural snobbery that superficially flirts with different cultural idioms from the dominant, central, and stable cultural preconceptions [8].

In contrast to these perspectives, this essay presents an alternative concept, that of transculturation. Following this concept, the cultural reality is not understood as this evasion towards a generic nebula described by cultural critics of the $90 \mathrm{~s}$, nor towards the absolute abstraction that preached Marxist criticism - aligning itself towards individual subjectivity. The concept of transculturation understands that specific and defined entities always determine the city's cultural reality - although in a continuous two-way process of contestation. In fact, the displacement and resettlement of different particularities is what shapes most of the urban environments in which we live in today.

The concept of transculturation was first coined by the Cuban anthropologist and intellectual, Fernando Ortiz in 1940, in his book Contrapunteo Cubano del Tabaco y el Azúcar [9] and has since been used by other Latin-American cultural critics. In his book, 
Ortiz begins his cultural critique by explaining two agricultural holdings of different economic, cultural, and social characters in which Cuba had been involved in since the beginning of its colonisation. On the one hand, there is the sugar trade -considered as something alien and imposed by its colonisers. In fact, the sugarcane is an imported plant, which has always been exploited by foreign control -first by the Spanish and later by American patrons. On the other hand, tobacco production represents the vernacular in Cuba. In contrast to sugar, tobacco is the native plant that Europeans discover thanks to indigenous customs. This was the contribution of native Cubans to Western culture. Despite the cultural differences between these two forms of production, for Ortiz the cultural interpretive horizon of Cuba lies precisely in the dialectic (or contrapunteo) between them. The dialectics between the sugar business imported by Europeans and the local Cuban use and customs of tobacco exported by Europeans is where postcolonial Cuban identity exists.

Throughout the second half of the twentieth century, the term transculturation has been used by two of the most important critical voices in Latin-American thinking: Peruvian writer and ethnologist José María Arguedas and literary critic Ángel Rama. For Arguedas [10], the notion of transculturation serves to penetrate deeply into the Peruvian cultural reality. One of Arguedas' most interesting findings was the realisation of how natives who had remained isolated from the colonisers' influence peculiarly suffered more disintegration and chaos because of new technological expansions and the countries progressive stride towards modernisation. Meanwhile, the natives who remained in prolonged contact with their colonisers somehow developed certain antibodies that constituted a mechanism of adaptation to this new wave of modernisation. In his reflection, Arguedas tries to demonstrate, beyond essential or foundational coherences, that cultural interaction is what arises criticality and thus ensures survival, whilst isolation on the other hand, is what weakens and mitigates populations.

On the contrary, Rama [11], appropriates the term transculturation to explain the narrative practices of certain Latin-American novelists situated in a complicated intersection between different linguistic, ethnic and social realities. More interestingly, Rama brings back this transcultural criticism to reflect on Latin American urban practices in his work La ciudad letrada. According to Rama [12], following the logic of colonisation, Latin American cities emerge as lettered -as the letter fixates on the norm upon which colonial cities were founded. According to Rama, these letters that appear as a delimiting judicial stipulation at the beginning, is later assimilated into a literary tradition of living in the city.

\section{A CRITIQUE TO HYBRIDISATION}

In Post-colonial studies, especially derived from French and British practices of colonisation, the concept of hybridization has been frequently referred to as a way to critically position oneself towards certain colonisation processes. The value that theoreticians in this field, such as Homi Bhabha, Gayarik Spivac and Nestor Garcia Canclini, most commonly attributed to hybridisation is its ability to act as a mechanism of liberation from colonial power. Particularly, Bhabha [13], argues that the assimilation of metropolitan works, traditions and genres in colonial contexts ends up hybridising, defiling and displacing them. Therefore, this assimilation dissolves and undermines the authority and coherence of the colonising processes, with a far greater effectiveness than even that of open resistance to the coloniser.

For Bhabha, the colonial relationship entails the dissolution of Western discourses by their continuous and inevitable interpretation in an alternative and diverse social, religious and cultural context. In this way, this dissolution becomes a two-fold process by which, the coloniser not only discursively conceives the colonised, but somehow the colonised in turn, 
also conceives the coloniser. The analysis of colonial discourse should also be a two-way process, able to both continue a resistance that rejects the fictionalisation of nationalist ideals and to infect impurity and propagate contamination to cause the progressive displacement of colonial authority.

In recent years, an extensive dissemination of Bhabha's critique to a multitude of distinct intellectual fields has been triggered because of the ingenuity and novelty of his reflection. However, the application of Bhabha's studies regarding a specific Latin-American context a colonial milieu with entirely different colonisation logic than to the one he based his studies on, is indeterminate. In this regard, philosopher Eduardo Subirats [14], explains that, "the anesthetisation of Latin American social and linguistic landscapes under the category of hybridisation, besides being intellectually rude, has been politically ambiguous. This concept has often been confused as a semiotic exchange between cultures, languages and different understandings as if its practice had been the result of a horizontal dialogue between equal parts, not the consequence of a conflict mediated by colonial violence, and their industrial and post-industrial heirs".

According to Subirats, hybridisation was also the process by which colonial disarticulation of communities occurred, as the erasure and destruction of cultural memories was conducted through the creation of a biologically and symbolically homogenous individual, thus preventing any anti-colonial resistance. Consequently, for Subirats, colonialguided syncretism and hybridisation guarantees a deeper rootedness of the colonial power.

On the other hand, for the sociologist Zymunt Bauman [15], the idea of hybridisation starts from the false assumption that there are definable and original cultural realities, this is, a category of cultural reality that actually does not exist at the present. Therefore, concepts such as hybridisation, mixing, blending, or grafting of cultures would involve a cultural space neatly divided into separate parcels roughly marked by the clear differences between interior and exterior and with borders to control the traffic between them. Following this, Bauman points out that if these transfers could really happen, the analysis of what is outside, this is, external to the object study, would be the result of an endless negotiation -highlighting the improbability for it to be conceived as such. In other words, if the translation generates a translated text, this text in turn generates its translator as a necessary derivative and so on and so forth.

Following another perspective, some theoreticians have talked about an anesthetisation of the term hybridisation. In some cases, this term is understood only and exclusively as a description of a formal configuration in which different influences, materials and procedures has been mixed. This criticism has been especially unfortunate in the field of architecture, where hybridization has often been confused with simple eclecticism. Architect Felipe Hernández [16], has highlighted the misappropriation of the term hybridisation in both the North-American and Latin-American academics. In many cases, the term hybridisation was equated with the eclectic postmodern of Graves or Venturi. For Hernández, a consequence of this misuse and misunderstanding of the term by certain architects has generated that "(hybridisation) has lost political efficacy and has been reduced to a problem of aesthetic syncretism, which is exactly what architectural hybridisation, as a cultural concept, is not". Considering these words from Hernández, for a productive use and with truly cultural and socio-political implications of the term, hybridisation must be separated from any type of aesthetic category. As the architect points out again: "buildings are not hybrid because they combine numerous architectural motifs, but because they emerge within and take part in the hybrid cultures where they happen to exist, and, as a consequence, they estrange the hierarchical structures that qualify them as inferior". 


\section{TRANSCULTURATION AS AN URBAN PRACTICE}

Transculturation understood within the Latin American tradition and from a certain distance from the term hybridisation from the discipline of postcolonial studies allows us to approach a new cultural critique of architecture and the city. On the one hand, transculturation can only be understood as a practice of confrontation and constant contestation, as a counterpoint of multiple dialectics, and not as a fusion or aesthetic mix. Patching together memories, materials, symbols and various means, it is a practice of constant negotiation, where the different cultural enunciations cause different cultural responses and in turn call for new spatial articulations. Therefore, transculturation cannot be understood as temporarily delimited or finished object, but as a continuous flow of practices, their contributions and responses over time. Often cultural studies have wanted to find in absolute certainty a certain logic of transculturation, but it does not make sense to talk about transculturation in a finished object. Transculturation is always a cultural becoming, a process; a practice. There might be a symptom or a glimpse of it appearing in a particular work, but we can only talk about transculturation in a holistic sense when it is related to fluidity and change.

Consequently, all available models for an architecture of transculturation are quite fragile. Transcultural processes generate different cartographies, imaginaries and dispositions in their various modes of appropriation of the city, as it is only in these fragile practices that we can find something comparable to what would be transculturation in architecture and urban space. We would like to introduce the work of Lina Bo Bardi in Brazil, one of the few countries with a broader cultural and ethnic diversity, as a precedent of an architecture able to relate to transcultural processes. However, if we analyse some of the built work by Lina Bo Bardi, we observe that the construction itself is not what symbolically manifests transculturation. Differently, the architecture arises as a framework for transculturation to happen. The transculturation is not realized autonomously by architecture, but in the fluctuating relationship between the individual and the space, between architecture and our way of inhabiting it. This is evident, for example in Bo Bardi's experiments in her own house in Morumbi, Sao Paulo, 1949-51, where she applies onto herself a kind of cultural process of experimentation. When Bo Bardi built her house, also known as the "casa de vidro", she had just arrived in Brazil. The house thus had the essence of something resembling the transience of a camp, a provisional stage. Bo Bardi said once that that house was like a "backpack", as it is like putting together once and again all necessary stuff for an imminent trip [17]. Hence the glass envelope containing the house is continuously contaminated by fluctuating internal scenarios where indigenous, African, Italian and Portuguese memories continuously mix, never totally fusing into any new stable cultural expression (Fig. 1). Following the example of Bo Bardi, transculturation in architecture cannot be considered as mere eclecticism, exotic taste or surrealistic de-familiarisation. Transculturation as a cultural conflict must be precisely understood as a critical process that prevents a cultural homogenization into a single realm or reality.

As transculturation deals with continuous interactions between different realities, its architectural expression is that of everyday life and not of institutional representation. This understanding of cultural representation is opposed to other very relevant modern Latin-American traditions, such as Mexican muralism. Muralism was probably the most successful cultural movement in Latin-America in its ability to begin a dialogue about identity.

It quickly spread throughout Latin-America, whilst simultaneously developing and maintaining an extraordinary relationship with architecture. However, muralism determined 


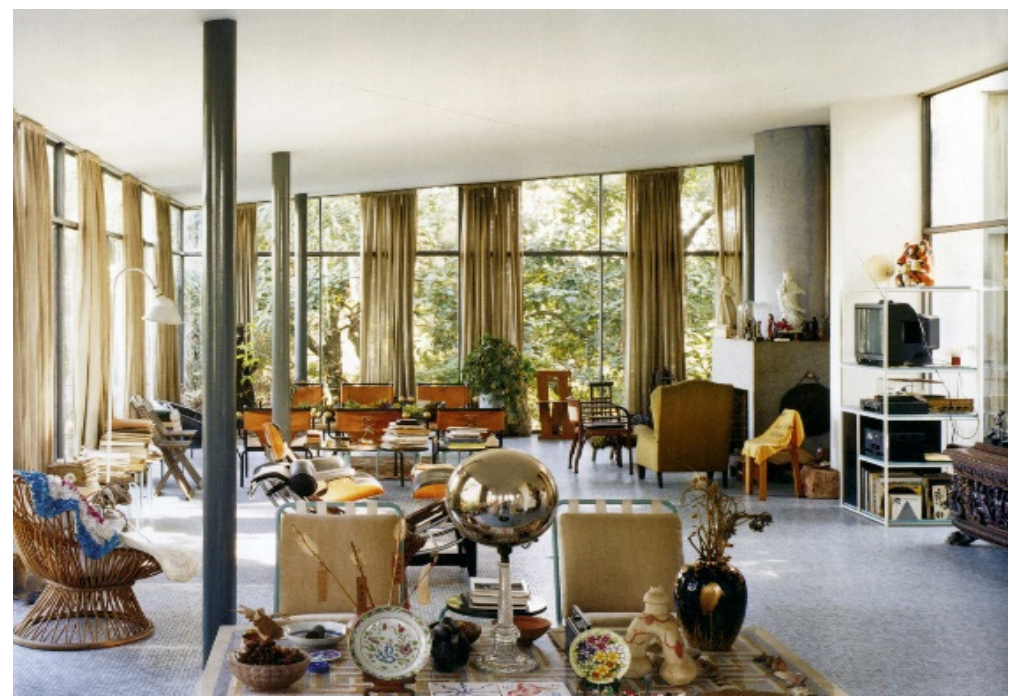

Figure 1: Two moments of the same space in Lina Bo Bardi's Casa de Vidro. (Revista 2G2424, 2002 and image by the author.)

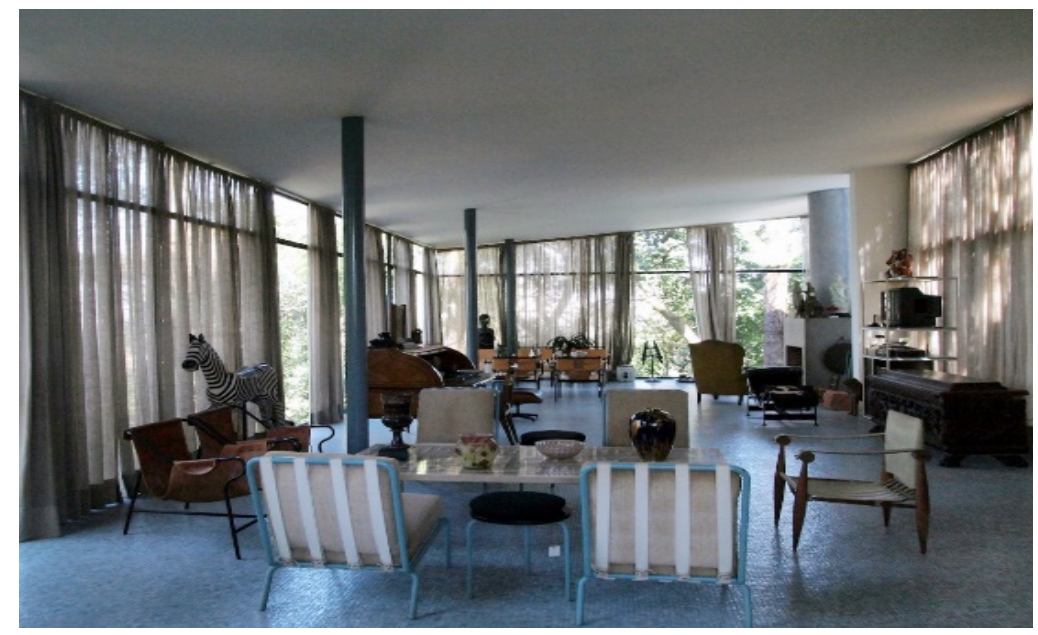

Figure 2: Two moments of the same space in Lina Bo Bardi's Casa de Vidro. (Revista 2G2424, 2002 and image by the author).

a fixed cultural image for the society being represented. This was the case for the celebrated UNAM library building in Mexico DF by Juan O'Gorman (1949-1951).

The formalisation of this building fully complied with international modernism, but its surface was covered by a mosaic of colour stones executed by O'Gorman himself representing a full cosmogony of Mexican culture [18]. But any attempt to establish a stable 
cultural representation, as muralism tried to do, is always an act of discrimination, inevitably leaving individuals and groups misrepresented, excluded, outside, while annihilating the fluctuation and continuous cultural dialectics that transculturation implies.

In contrast, in Bo Bardi's architecture, the building does not claim any representational relevance, but it acts as an interface that makes inhabitants practices of exchange and counterpointing possible. In Bo Bardi's Museum of Art of Sao Paulo (MASP, 1958-1972), this attitude is taken to an urban scale. The building, located in the very dense area of Avenida Paulista is lifted over the ground to free a public square on the belvedere facing the back, accentuating the dramatic change in height. All the programme of the building is located either above the ground level or underground. Following this position towards the city, transculturation is not happening through the building, but through the practices of the citizens in that now liberated space for them.

In her drawings, Bo Bardi represents these practices as situations of a carnivalesque expression, where different unexpected performances arouse constantly (Fig. 2). In this manner, the cultural representation is transferred from the building to the inhabitant. This implies that it is in the practices of these individuals and groups of individuals in this public space that exchanges and counterpoints unfold in a conflicting and non-unitary way, preventing unification as determined by transculturation aspirations. The MASP urban space is thus a breath of fresh air in Avenida Paulista, where people crafting, organising informal markets, skating, dancing, playing music or performing in unsuspected ways can be found daily (Fig. 3). In a socially distressing city such as Sao Paulo, this is a space where culturally conflicting practices unravel and occur as a recognition of reciprocal difference.

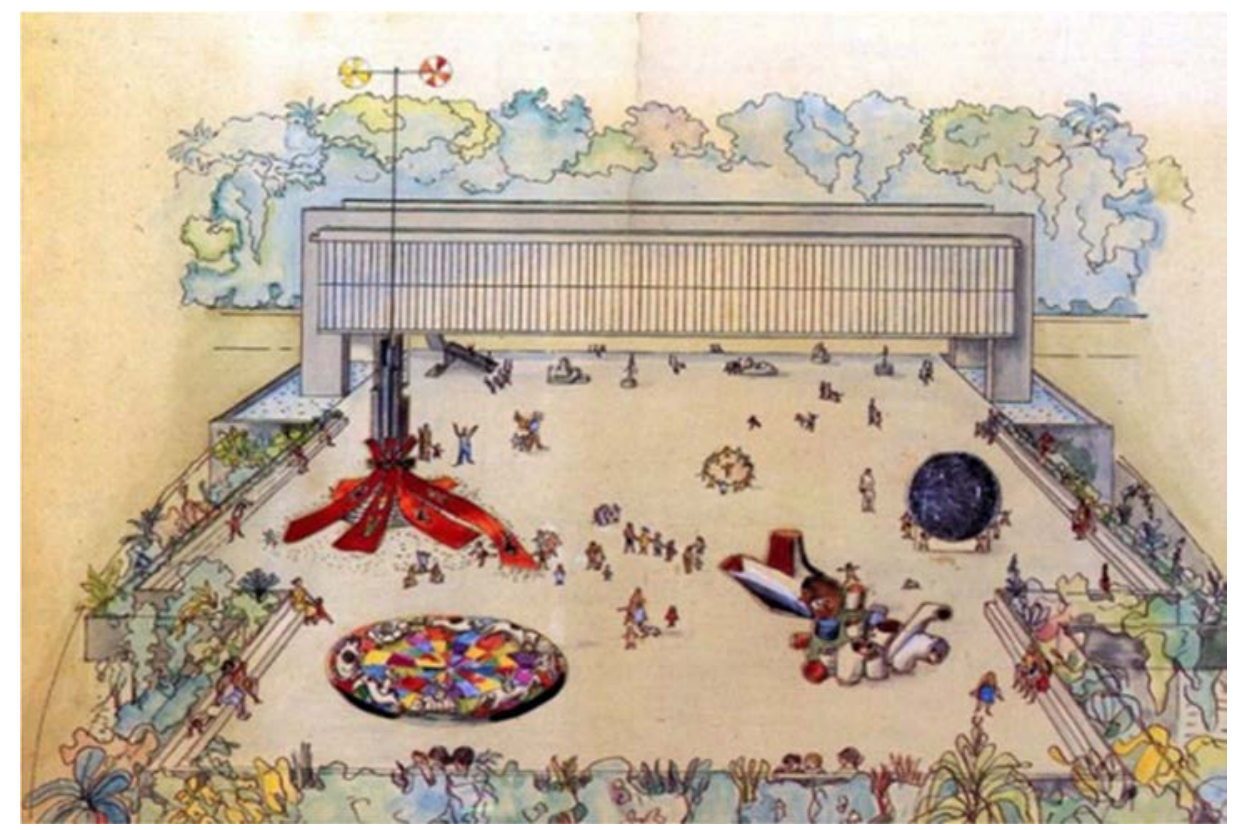

Figure 3: Lina Bo Bardi MASP. (Fundación Lina \& Pedro Maria Bo Bardi and photograph by Iñigo Bujedo Aguirre.) 


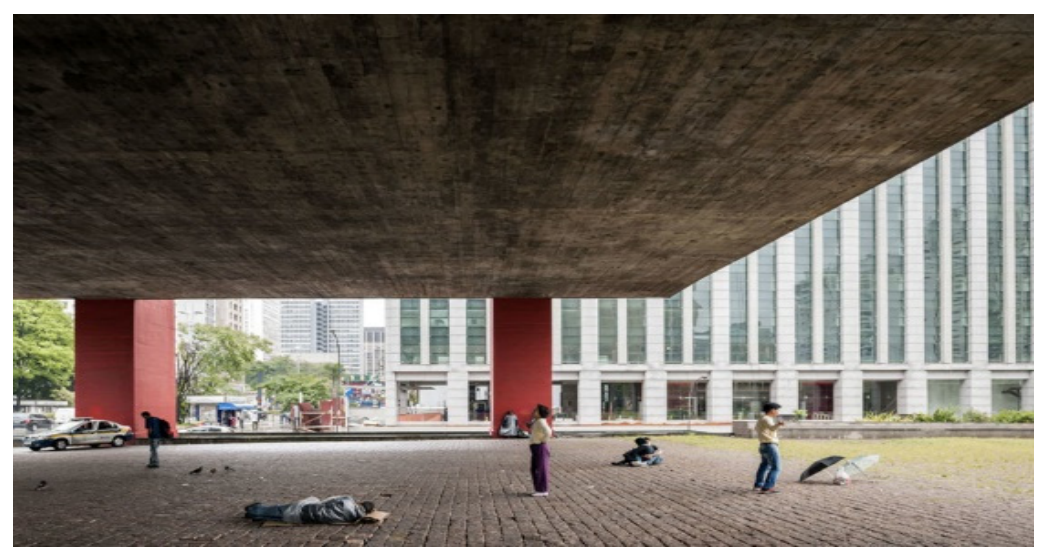

Figure 4: Lina Bo Bardi MASP. (Fundación Lina and Pedro Maria Bo Bardi and Photograph by Iñigo Bujedo Aguirre.)

\section{TRANSCULTURAL COLLECTIVE URBANISM}

A more contemporary example of urban action negotiating cultural difference and sociospatial polarization is the small Gillet Square in the Dalston neighbourhood in East London. Unquestionably, London is one of the more culturally diverse cities in the world, and its public space is the place where cultural negotiation happens on the daily. However, the neoliberal consequences that permeate through all of London's urban fabric jeopardises these negotiations through the commodification and privatization of public spaces. The peculiarity that highlights this square from other public places is its ability not only to allow a dialogue between different ethnic groups and social strata in both its design, construction process and subsequent use, but also to introduce time as a factor that facilitates people's appropriation of the public space in their practices. But before going into details about this square, we need to better understand its location in the city and the processes it has been involved in.

Located in North East London, the Dalston neighbourhood is a residential area with eighteenth and nineteenth century row houses and mid-twentieth century housing blocks that have been inhabited for years by different waves of migrants. Firstly, by a large Jewish community from central Europe that settled in at the end of the nineteenth century that progressively moved to other city locations. Then by a large group of Caribbean migrants who arrived in the neighbourhood in the 50s and 60s to occupy the spaces left over. Later came the Turkish and Vietnamese and more recently the Polish. These different migrant flows, passing through this neighbourhood has gradually left in its wake, one of London's most ethnically diverse neighbourhoods -visually represented by a tradition of very unique shops and restaurants responding to all the different cultures that have been part of its evolving urban heritage. London City Council [19], aware of possible tensions in this very diverse neighbourhood decided in 2003 to support an old district project to regenerate an existing car park and transform it into the main public space for the neighbourhood.

The most attractive element in the initial public space design was the high level of participation in the decision-making process with various parties involved. This initiative started with the establishment of the district of Hackney in 1993, when a cooperative of builders and architects, the Collective Building Design (CBD), outlined the initial ideas for a new square in Gillett Street. After five years of meetings, mediated by the district board 
for cooperative development, the Hackney Cooperative Development (HCD) [20], the proposal was outlined. One of the parking lots located in a leftover space between existing buildings was going to be converted into the main public space for Dalston (figure 4). This first led to the construction of ten market kiosks designed by architects Hawkins and Brown. Instead of a big intervention with a fully resolved design to be built on the city suddenly, the strategy in Gillett square was to articulate a series of minor progressive changes. These kiosks began the active character that would later define this public space without even changing the pavement, that remained as asphalt for a long time (Fig. 5).

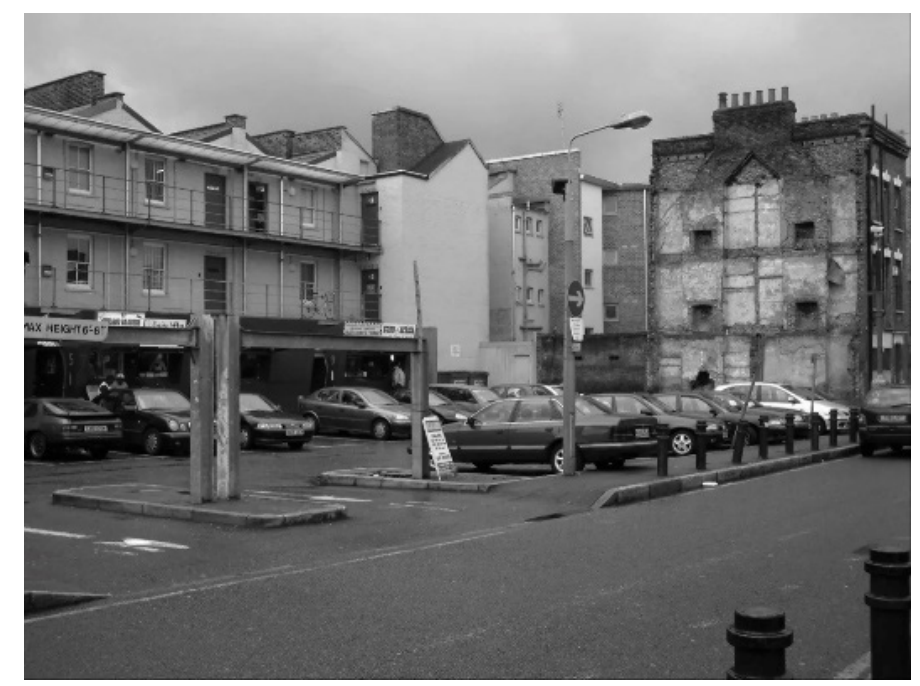

Figure 5: Gillett Square as a parking and after its reconversion. (Source: Black Stock www.blackstockpr.com and Hawkins and Brown www.hawkinsbrown.com.)

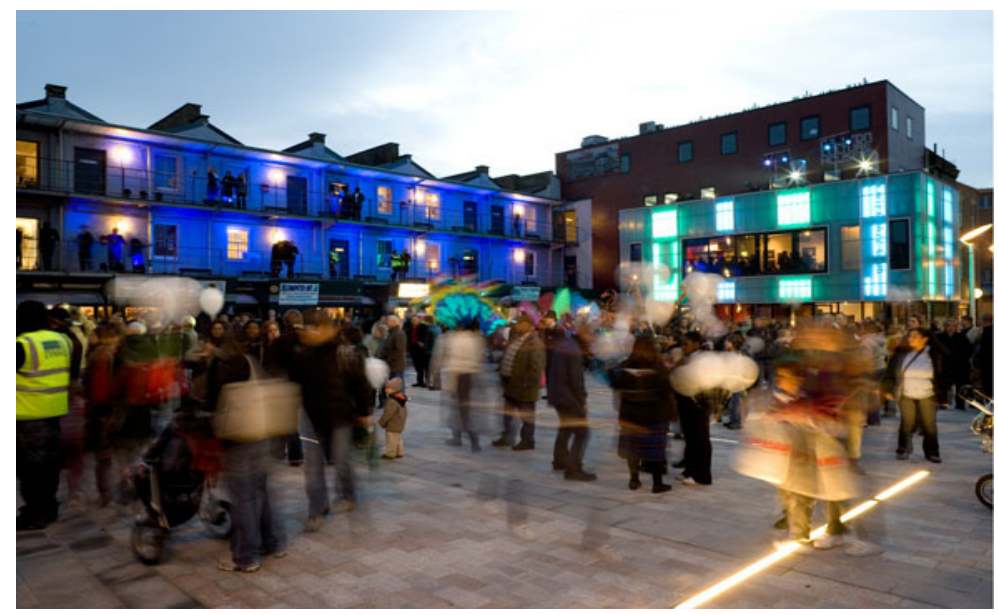

Figure 6: Gillett Square as a parking and after its reconversion. (Source: Black Stock www.blackstockpr.com and Hawkins and Brown www.hawkinsbrown.com.) 
Step by step other public and private interventions were promoted. The overall public space project increased in scale, and with it the number of parties involved. Following the first set of successful interventions, the HCD decided to extend the design scope by proposing to the cooperative to renovate a nearby factory to house a Culture Centre for the neighbourhood. Later on, a mix of public and private investment allowed for the construction of a mixed-use building in the north side of the square that would support the rest of the project. Among the section of new private investors, not only where private developers involved, but also several non-profit associations that would share the use of this building. The incremental development of the site allowed a better understanding of the project by the people, that found essay to appropriate the elements that little by little started to be available for them. This is also reinforced through different activities organised by HCD, Groundwork East London and the local networks, members of the Local Strategic Partnership and the neighbour's forum. The aim was to obtain the participation and opinion of all the social and ethnic strata that compose the neighbourhood before finalizing the final plan executed by landscape architects Whitelaw Turkington.

All this collaborative process of design and construction that united different participatory parts were not abandoned with the pass of the time and was later carried forward with the use of this new public space. The open possibility of renting projectors, movable elements, urban or sound furniture through the HCD facilitated diverse cultural practices to happen. All these activities help the interaction and negotiation between the distinct ethnic groups and social strata. Through playing, dancing, listening, tasting or painting, cultural frictions make a positive impact that attenuate social conflict.

Finally, in line with transculturation theory, what is common to Bo Bardi's MASP and the Gillet Square is the use of cultural conflict as a driving force to generate urban integration. Instead of rejecting this conflict and substituting it by a homogeneous cultural representation, whether multicultural or not, both projects work on exploiting this conflict by generating the right framework to showcase the diversity and plurality of cultural practices that exist in the city. It is precisely through the unveiling of these cultural practices, by building cultural awareness through active participation can we as citizens eradicate secular ignorance and establish a socially sustainable and truly democratic city.

\section{REFERENCES}

[1] Koolhaas, R., The Generic City. S, $M, L, X L, 010$ Publishers/The MonacelliPress:New York, pp. 1239-1264, 1995.

[2] The Anywhere Conference of 1992, where some of the most prominent architects of the time participated, showed how most of the speakers kept a strong contextual position. One of the most remarkable speeches at that conference was Rafael Moneo's text "The murmur of the site". Architect Rem Koolhaas also presented his text "The generic city" at this conference that could be understood as an answer to Moneo's speech. Davison, C., Anywhere, Any Corporation: New York, 1992

[3] Augé, M., Non-Places: Introduction to an Anthropology of Supermodernity, Verso: London, 1995.

[4] Koolhaas, R., The Generic City. Opuscit, p. 1248

[5] Virilio also presented a paper on this topic at the Anywhere Conference. His most important work on this idea is: Virilio, P., The Aesthetics of Dissapearance. New York: Semiotexte, 1991.

[6] Koolhaas, R., Junkspace. October, Vol. 100, Spring, pp. 175-190, 2002. 
[7] Although originally published in French in 1981, Baudrillard's Simulacreet Simulation had a great impact in the anglo-saxon academia after its translation in 1994. Baudrillard, J., Simulacra and Simulation, The body in theory: Michigan, 1994.

[8] Bauman, Z., Community: Seeking Safety in an Insecure World, Wiley: London, 2002. A.Touraine, Can We Live Together?: Equality and Difference. Stanford, Calif.: Stanford University Press, 2000. Slavoj, Z., "Multiculturalism, or, the cultural logic of multinational capitalism”. New left review, I/225, Sept-Oct, 1997.

[9] Ortiz, F., Cuban Counterpoint: Tobacco and Sugar, Durham: Duke University Press, 1995.

[10] Arguedas, J. M., Formación de una cultura nacional indo-americana, Siglo XXI: México DF, 1976.

[11] Rama, A., Writing Across Cultures. Narrative Transculturation in Latin America, Durham: Duke University Press, 2012.

[12] Rama, A., La ciudad letrada, Ediciones del Norte: Hanover, 1984.

[13] Bhabha, H., The Location of Culture, Routledge: London, 1994.

[14] Subirats, E., Arte popular y cultura digital. Una última visión del paraíso, FCE: Méjico, p. 181, 2004.

[15] Bauman, Z., Culture as praxis, Sage Publications: London, p.79, 1999.

[16] Hernández, F., On the notion of Architectural hybridization in Latin America. The Journal of Architecture, Spring 7, pp. 80-82, 2002.

[17] González de Canales, F., Experiments with life itself. New York. Actar, p. 14, 2012

[18] This was celebratedly described by Hitchcock in his review of the International Style. HITCHCOCK, H.R., Biblioteca central. Latin American Architecture since 1945, MOMA: Nueva York, pp. 76-77, 1955.

[19] Glancey, J., Plastic utopia, The Guardian, Monday 4 April 2005 Online. www.theguardian.com/artanddesign/2005/apr/04/architecture.communities. Accessed on: 2 Feb. 2012.

[20] Hackney Cooperative Development HCD - Pioneer Community Economic Development. http://www.hced.co.uk/webdocs/partners.html. Accessed on 2 Feb. 2012. 